\title{
Modos de VIDA TRANSNACIONALES, prácticas organizativas y remesas sociales en el centro de Perú
}

\author{
NORMAN LONG \\ Universidad de Wageningen, Países Bajos \\ normanlong@hotmail.com
}

Resumen

[STE ARTÍCULO EXAMINA CUESTIONES RELACIONADAS CON LA MIGRACIÓN Y LOS MODOS DE VIDA transLlocales en Perú. La migración constituye un proceso continuo, a través del espacio y el tiempo, de adaptación entre las redes familiares y comunitarias, y requiere de una exhaustiva comprensión del carácter de la translocalidad, tal como la experimentan los actores involucrados en el proceso. Con base en un trabajo etnográfico diacrónico y genealógico, se emplea un análisis centrado en el actor para comprender las relaciones y prácticas culturales que intervienen en la articulación de los migrantes con quienes se quedan en el lugar de origen.

PALABRAS CLAVE: migración, análisis del actor, genealogía, remesas, Perú.

\section{Transnational livelihoods, Organizing Practices, AND Social Remittances in Central Peru}

\begin{abstract}
This article examines issues of migration and translocal livelihoods in Peru. Migration constitutes an ongoing process of adaptation between networks of family and community over space and time, and requires an in-depth understanding of the nature of translocality as experienced by the particular actors involved. Based on diachronic genealogical ethnographic work, it adopts an actor-oriented analysis to understand the relations and cultural practices involved in articulating migrants with those who stay home.
\end{abstract}

KEY WoRDs: Migration, actor-oriented analysis, genealogies, remittances, Peru.

\section{Revista Colombiana de Antropología}

Volumen 44 (2), julio-diciembre 2008, pp. 337-372 


\section{INTRODUCCIÓN ${ }^{I}$}

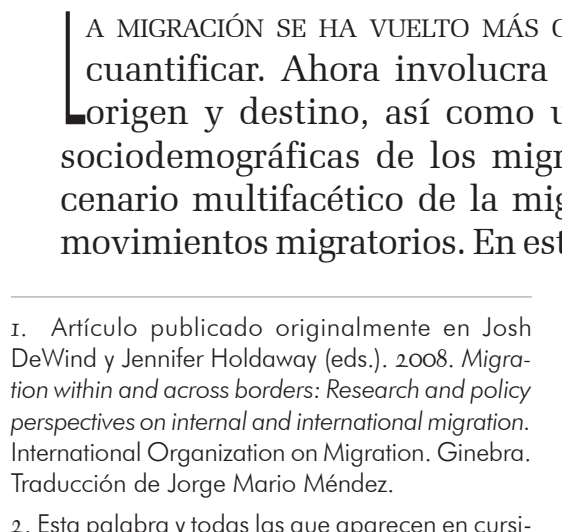

va están en español en el original (N. del t.). relacionadas con la migración y los modos de vida translocales en el centro de Perú. En lugar de intentar delinear las características estructurales generales de los patrones contemporáneos de migración interna e internacional, se emplea un análisis centrado en el actor que permite comprender los complejos conjuntos de relaciones y prácticas culturales que intervienen en la articulación de los migrantes con las familias y paisanos ${ }^{2}$ que permanecen en su lugar de origen. La migración constituye un proceso continuo, a través del espacio y el tiempo, de adaptación entre las redes familiares y comunitarias, y requiere de una exhaustiva comprensión del carácter de la translocalidad, tal como la experimentan los actores específicos involucrados en el proceso.

La parte principal de este artículo se centra en dos descripciones etnográficas: la primera aclara la utilidad de un método de estudio de caso diacrónico y genealógico para comprender la dinámica intergeneracional de las empresas multifamiliares y de la migración; y la segunda demuestra la necesidad de centrarse en el modo en que las prácticas y las interpretaciones culturales modelan las vidas y relaciones en curso de miembros de la familia que se encuentran "lejos". Después de esto, en la parte final se aplican los hallazgos derivados de estos ilustrativos casos a la cuestión de las remesas de los migrantes. En relación con esto, me propongo demostrar la necesidad de reconocer por completo la naturaleza socialmente construida de las remesas. 
REDES, MODOS DE VIDA Y CONSTRUCCIONES CULTURALES DE "COMUNIDAD" DE LOS MIGRANTES AL INICIO DEL NUEVO MILENIO

N I997 INICIAMOS UN NUEVO ESTUDIO ${ }^{3}$ DE LAS REDES, LOS MODOS DE VIDA

- y los modos de organización comunitaria de los migrantes que habían sido el foco de la investigación que llevamos a cabo en el centro de Perú en la década de I970 (Long y Roberts, I978 y I984; Altamirano, I984b; Laite, I982). Aun cuando el proyecto abrió nuevos caminos, particularmente en lo relativo

3. La investigación recibió el apoyo del Programa de Investigación Neerlandoisraelí (Nirp por su sigla en inglés) y la coordinamos Teófilo Altamirano (Universidad Católica, Lima), Moshe Shokheid (Universidad de Tel-Aviv, Israel) y Pieter de Vries y yo (Universidad de Wageningen). Dos investigadores de doctorado peruanos (Carla Tamagno y Manuel Gilvinio) y un investigador danés (Ulla Berg) llevaron a cabo un detallado trabajo antropológico de campo.

a los problemas de migración internacional, transnacionalismo y la difícil situación de las familias desplazadas internamente como resultado de la guerra civil de Sendero Luminoso, brindó también la oportunidad de replantear algunas preguntas fundamentales en nuestro trabajo previo (Long y Roberts, I978 y 1984).

La investigación se basó en informes previos sobre las contribuciones de los migrantes y de sus vínculos con el desarrollo de la región del Mantaro. No obstante, se anticipó que habrían tenido lugar importantes cambios en la organización social, los modos de vida y el sentido de pertenencia regionales, debido a la inestabilidad política y económica de los quince años anteriores, durante los cuales Sendero Luminoso -revolucionarios de línea maoísta- y el ejército peruano combatieron por el control de las regiones montañosas y de los asentamientos urbanos estratégicos del país.

Esta situación llevó a un gran éxodo de personas hacia zonas seguras y centros urbanos, lo que generó que más de un millón de peruanos de las regiones montañosas resultaran desplazados internamente; estos encontraron refugio en pueblos ubicados en otras zonas del país o en comunas que crecieron alrededor de las ciudades principales. Al mismo tiempo, el número de migrantes más pobres o de estratos más bajos que abandonaban el país se elevó, y siguió elevándose hasta 2000, cuando se calculó que aproximadamente dos millones y medio de peruanos -equivalentes a Io\% de la población- residían fuera de su país 
de origen. Esto provocó una reacción en cadena, en el sentido de que muchas otras personas, al presenciar estos acontecimientos alarmantes, decidieron migrar también, y algunos lo hicieron hacia otros países.

Una vez que hubo disminuido la violencia política en Perú, los migrantes se enfrentaron a la elección entre retornar a sus comunidades de origen, permanecer en donde estaban o seguir moviéndose. Una cantidad considerable optó por seguir moviéndose. Por tanto, era crucial que nuestros estudios contemplasen la nueva posibilidad de la migración entre países, dado que esta opción emergió, de manera casi espontánea, a partir de las experiencias migratorias desencadenadas por la insurgencia.

\section{Reconceptualizar la migración desde la perspectiva del actor}

Así, NUESTRA INVESTIGACIÓN SE PROPUSO ADOPTAR UNA PERSPECTIVA ACERCA de la migración que tuviese en cuenta: I) la multiplicidad e interconexión de distintos tipos de migración y modos de vida; y 2) la importancia de estudiar los procesos de globalización desde el punto de vista de los actores sociales situados en la "periferia". Los estudios sobre la migración suelen examinar la interacción histórica de diferentes flujos y elecciones migratorias como si fuesen producto de algún tipo de movimiento espacial claramente definido, intencional y coherente, moldeado por una lógica externa vinculada a las transformaciones de los mercados laborales y los sistemas de producción y tecnología, o a orientaciones y valores culturales asociados con la "modernidad", en lugar de ser el resultado de "apremiantes preocupaciones personales" experimentadas por los actores sociales y que influyen sobre estos. Por el contrario, en el análisis de los problemas de la migración y la globalización adoptamos un enfoque centrado en el actor ${ }^{4}$, que

le da prioridad metodológica al

4. Para una exposición de los fundamentos teóricos y metodológicos de un análisis del cambio y desarrollo social centrado en el actor, véase Long y Long (I992), Arce y Long (2000) y Long (200I). examen de las situaciones cotidianas en las que los individuos $\mathrm{y}$ los grupos intentan resolver los problemas de sus modos de vida. Consideramos que esto nos permitiría comparar las diferencias entre hogares y comunidades locales, y estudiar los 
procesos mediante los cuales se entretejieron las redes de migrantes, los modos de vida y las ideas de "comunidad" y de sentido de pertenencia. Por supuesto, este punto de vista no presupone elecciones racionales, pero sí reconoce plenamente el papel de la acción, el conocimiento y las prácticas organizativas de los actores situados en sociedad.

En publicaciones anteriores he defendido la idea de que "las prácticas locales incluyen macrorepresentaciones y son configuradas por escenarios distantes en el tiempo y el espacio, pero estos macrofenómenos sólo son inteligibles en contextos situados”, es decir, que "se cimientan en los significados que se les confieren a través de las experiencias vitales y los continuos dilemas de hombres y mujeres” (Long y Long, I992: 6-7). Así, aplicando esto a la migración, puede afirmarse que es necesario familiarizarse con las prácticas, las narrativas y los esquemas de pensamiento que manifiestan las personas con respecto a la movilidad geográfica y social; y que esto debe aplicarse tanto a lo que podría llamarse actores "legos", como a los "expertos": los investigadores y personas encargadas de formular políticas, que generan modelos y tipologías de la migración en un intento por describir sus elementos fundamentales, comprender cómo está constituida y delinear sus consecuencias. Esto sugiere que, en vez de adoptar una forma de positivismo distante que se proponga categorizar los tipos de migración y establecer diferencias claras entre ellos -por ejemplo, migración laboral "circular" temporal o de largo plazo, migración "paso a paso", migración "interna permanente" rural-urbana, rural-rural o urbana-urbana, en contraposición a la migración “internacional”-, quizá sería mejor examinar los flujos de migración y los patrones de movilidad geográfica desde el punto de vista de los problemas relacionados con la reproducción o transformación de las estrategias del modo de vida y las identidades sociales o nociones de "sentido de pertenencia”. La migración es, en sí misma, un punto de partida demasiado vago. Incluso, si iniciamos la investigación con el interés de entender el impacto de determinados cambios económicos, políticos y culturales asociados a la emergencia de un mundo cada vez más "global” y "globalizante", en el que la movilidad geográfica, el transporte veloz y la transmisión instantánea de información son la regla, ¿no sería un mejor comienzo darle significado a estos procesos en el contexto de las circunstancias de la vida cotidiana en medio de las cuales se presentan? En resumen, los anteriores 
son argumentos a favor de unos estudios etnográficos exhaustivos que le permitan al investigador capturar la elaboración y reelaboración continua de la vida social y cultural de quienes están "en movimiento".

A continuación presento dos breves descripciones etnográficas que abordan las relaciones translocales y pueden ayudar a dilucidar mejor la utilidad de la perspectiva que adoptamos. La primera explica la utilidad que tiene un método de estudios de caso diacrónico y genealógico para la comprensión de la dinámica de los múltiples modos de vida familiares. La segunda plantea la necesidad de atender la manera en que las prácticas e interpretaciones culturales configuran las vidas y relaciones en curso de miembros de la familia que están físicamente situados a una gran distancia entre sí, más allá de las fronteras nacionales, a saber, en un vecindario pobre de la ciudad de Huancayo, en la zona montañosa central de Perú, y en la ciudad de Milán, en Italia.

DOS DESCRIPCIONES EXTRAÍDAS de la investigación en Perú

\section{Las empresas múltiples: de lo "local" a lo "transnacional"}

Mi PRIMER EJEMPLO ES EL DE UNA EMPRESA MÚLTIPLE FAMILIAR, EN LA ZONA montañosa del centro de Perú, que investigué por primera vez a inicios de la década de 1970. La empresa combinaba varias actividades económicas que abarcaban desde la agricultura comercial en pequeña escala y la producción pecuaria -también tuvo un breve periodo de manejo de estanques de peces que tuvo un final triste cuando personas del pueblo envenenaron a todos los animales-, hasta la administración de una tienda, un restaurante, una estación de gasolina y una flota de camiones. Esta empresa múltiple funcionaba con base en una distribución de tareas entre miembros de la familia Jiménez. Sus actividades financiaron la educación de varios hijos, quienes finalmente migraron a los Estados Unidos, mientras que otros miembros de la familia se mudaron a Lima y a Trujillo, en la costa.

En ese entonces yo estaba interesado primordialmente en examinar la manera como redes sociales específicas, basadas en 
el parentesco, la afinidad, el compadrazgo y la amistad, operaban tanto favoreciendo como descartando determinadas decisiones estratégicas. Esto se acentuaba por el hecho de que Jiménez estaba en conflicto con la comunidad acerca de la legitimidad de sus adquisiciones de tierras. El caso mostró que las decisiones que Jiménez tomó fueron el resultado de sus respuestas a determinados dilemas y exigencias contingentes, y no fueron producto de estrategias premeditadas y cuidadosamente planeadas. En este sentido, era crucial la participación de lazos sociales existentes o la creación de unos nuevos. De lo que yo no estaba muy al tanto en ese momento era de la manera como la inversión de Jiménez en la educación de sus hijos generaría nuevas relaciones externas que resultarían efectivas y, al mismo tiempo, llevaría a la desaparición de la empresa original; pero es frecuente que las diferencias intergeneracionales en las empresas familiares ocasionen que estas empresas finalmente se "autodestruyan".

La genealogía I es una fotografía de la familia Jiménez en 1972, en la que se señalan los miembros de la familia que participaban activamente en la empresa y sus lugares de residencia.

La empresa múltiple funcionaba con base en la distribución de tareas entre miembros del grupo familiar Jiménez. Sus actividades financiaron la educación de varios hijos, quienes finalmente migraron a los Estados Unidos, mientras que otros miembros de la familia se mudaron a Lima.

Casi tres décadas después, muchas cosas han pasado. La violencia producida por el movimiento Sendero Luminoso llegó a su punto más alto en las zonas montañosas entre i989 y i994, momento en que su líder fue capturado y encarcelado. La economía había sufrido una fuerte caída, exacerbada por el incremento de la deuda nacional debido a grandes importaciones de comestibles más baratos, y la producción agrícola y pecuaria experimentó un descenso. La generación más joven de la familia Jiménez se encontraba ahora dispersa debido a la migración interna e internacional, y el negocio de camiones, bajo la administración de Atilio, uno de los hijos, había trasladado su centro de operaciones al puerto de Trujillo, en la costa norte de Perú.

A inicios de 1998, cuando vi a Jiménez, el padre, por última vez, éste era un anciano de noventa y tres años, débil y enfermo, quien, junto a su hija Hilda, con dificultad intentaba abrirse paso entre la multitud para celebrar la fiesta de san Sebastián, la celebración 


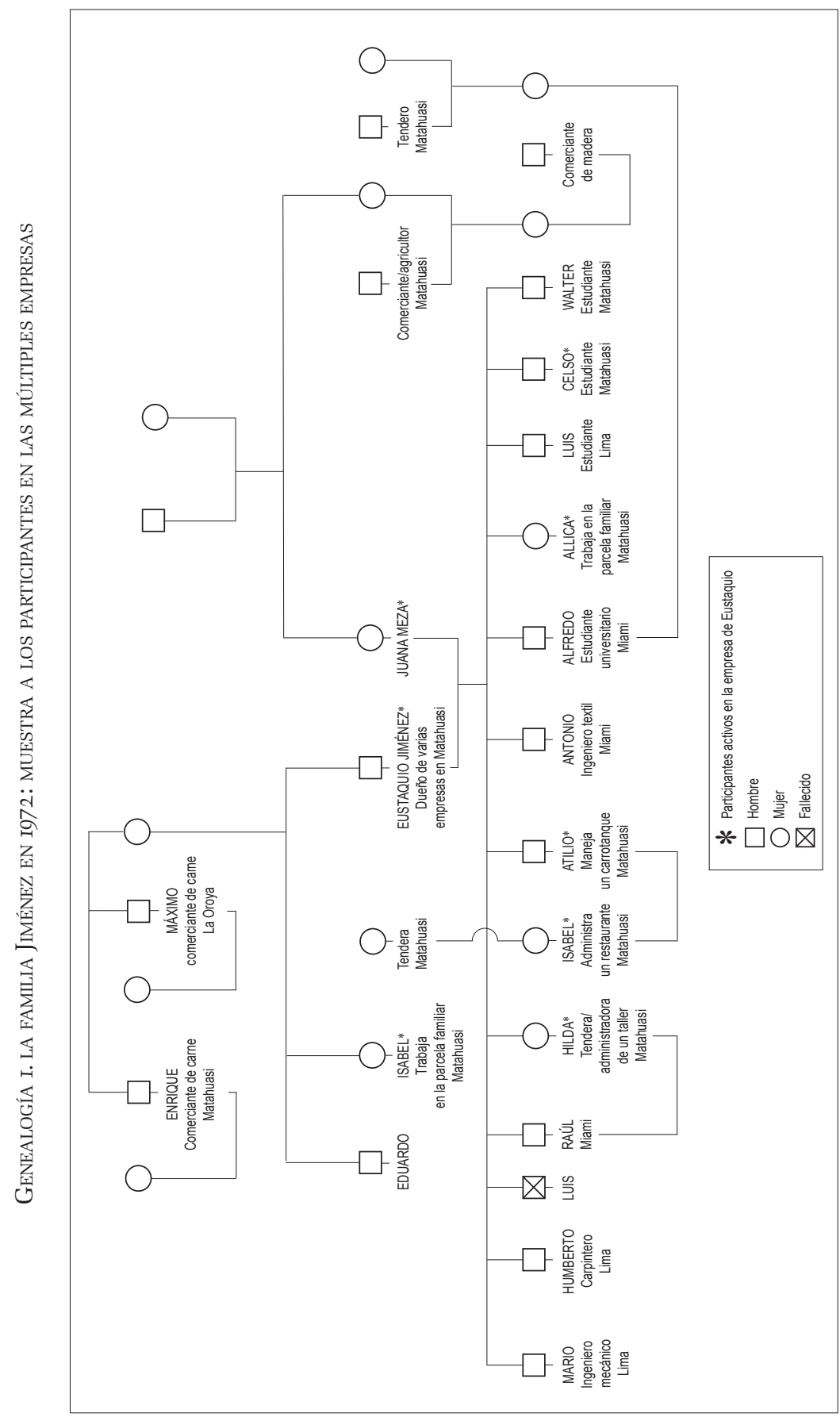


religiosa más importante del pueblo de Matahuasi. Aunque la infraestructura de la estación de servicio se conservaba intacta, ya no se vendía gasolina. No obstante, la tienda en la casa de Hilda estaba bien surtida con frutas, pan y artículos enlatados. En la década de 1980, Hilda había abierto, en el pueblo cercano de Concepción, un salón de belleza que funcionó bien durante algunos años, pero a inicios de los años I990, en el punto más alto de la violencia en Perú, el salón y el resto de la empresa sufrieron una súbita caída. Para I995, tanto el restaurante como la tienda, la estación y el salón de belleza habían cerrado, aun cuando arrendaron el restaurante y la oficina pegada a la estación de servicio. Las únicas actividades generadoras de ingresos que le quedaban a la antigua empresa familiar eran la granja, administrada por Walter, uno de los hijos, y los camiones que las hijas Allica e Hilda usaban para transportar mercancías bajo contrato.

La genealogía 2 muestra cuál era la situación en I998. Sólo tres de los once hijos de Jiménez permanecieron en el pueblo ocupándose de lo que quedaba de la empresa original. Los demás vivían ahora en Lima, en Trujillo, en el sur de los Estados Unidos y en Europa. Los esquemas de las genealogías 2a, 2b y 2c proporcionan información acerca de las diferentes ramas de la tercera generación de descendientes y permiten apreciar como los factores educativos, ocupacionales, maritales y de movilidad espacial, en especial la migración al extranjero, han cooperado para ocasionar la desaparición de la que originalmente fuera una empresa múltiple muy exitosa; y, al mismo tiempo, generaron un conjunto completamente nuevo de negocios y ocupaciones profesionales extralocales, tanto en Perú como en Estados Unidos.

\section{Genealogías familiares trigeneracionales}

L CASO DE LA FAMILIA JIMÉNEZ PONE DE RELIEVE LA VENTAJA DE ADOPTAR

- un método diacrónico intergeneracional de estudio de caso que

- examine las trayectorias del modo de vida y las historias de migración de miembros individuales de las familias. Para esto es útil centrarse en la reconfiguración de redes e intercambios entre los individuos y las familias, que se da en el paso de la generación de los mayores a la de sus descendientes. En este caso tuve la suerte de contar con información de referencia de la década de I970. 


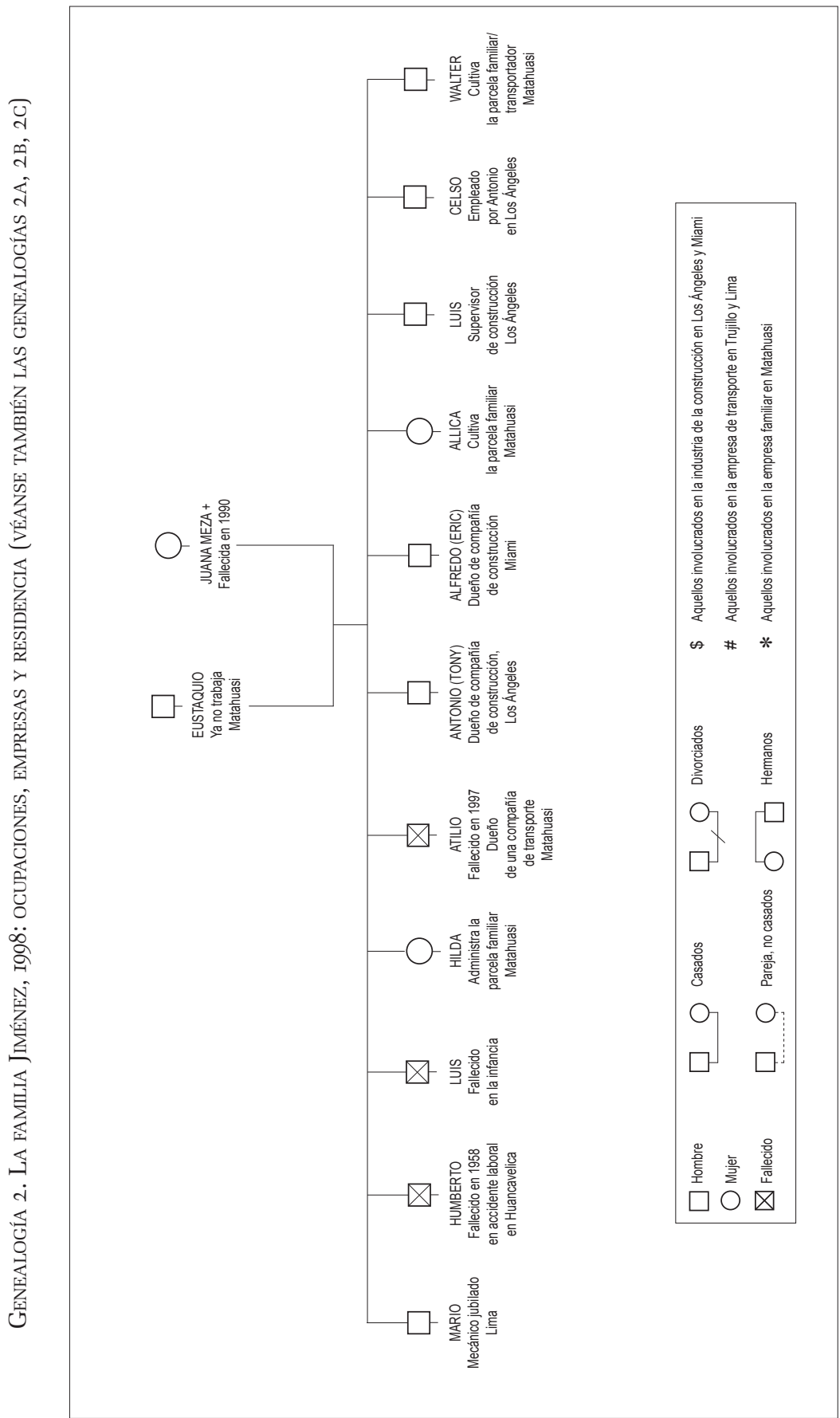




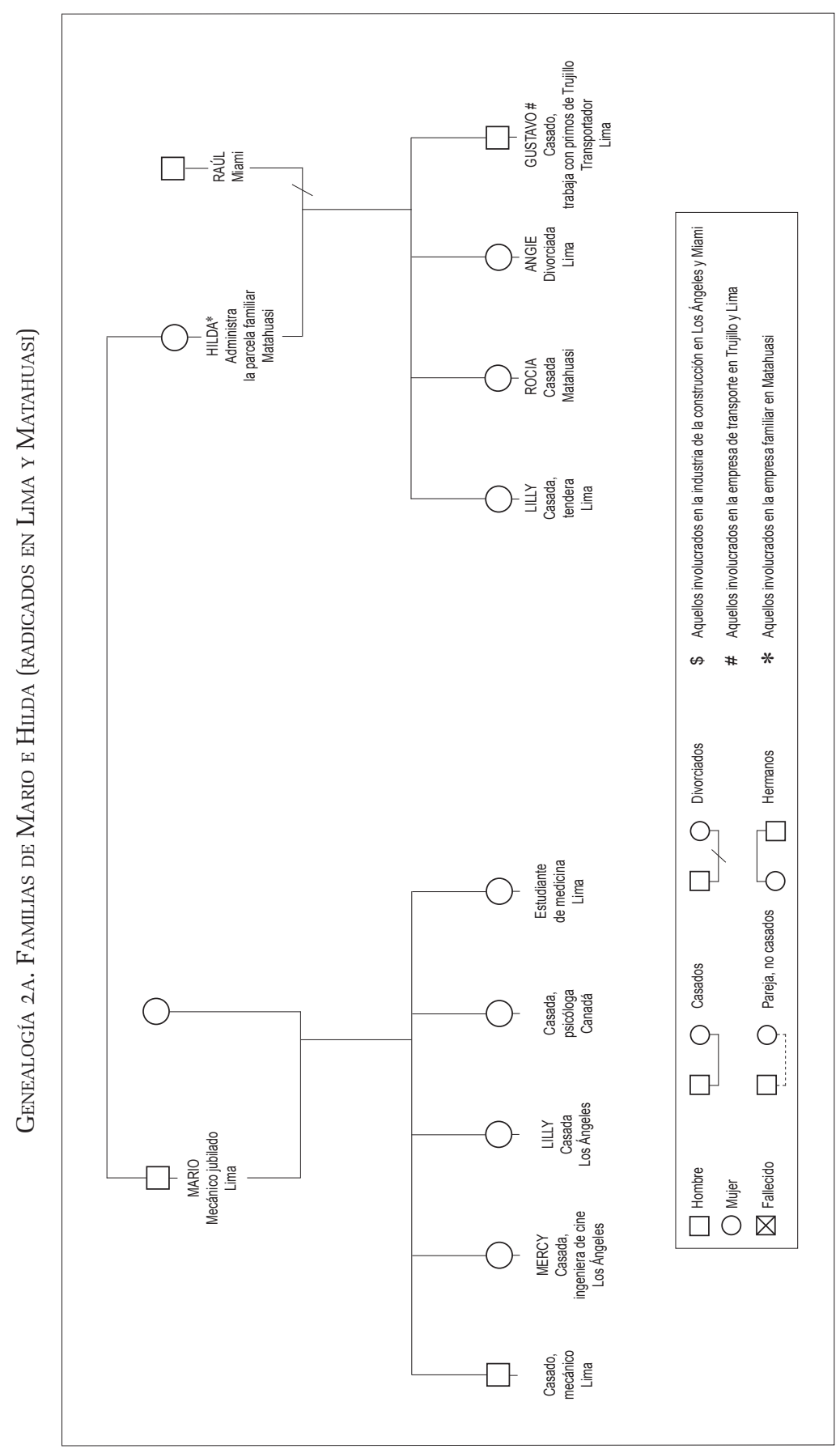




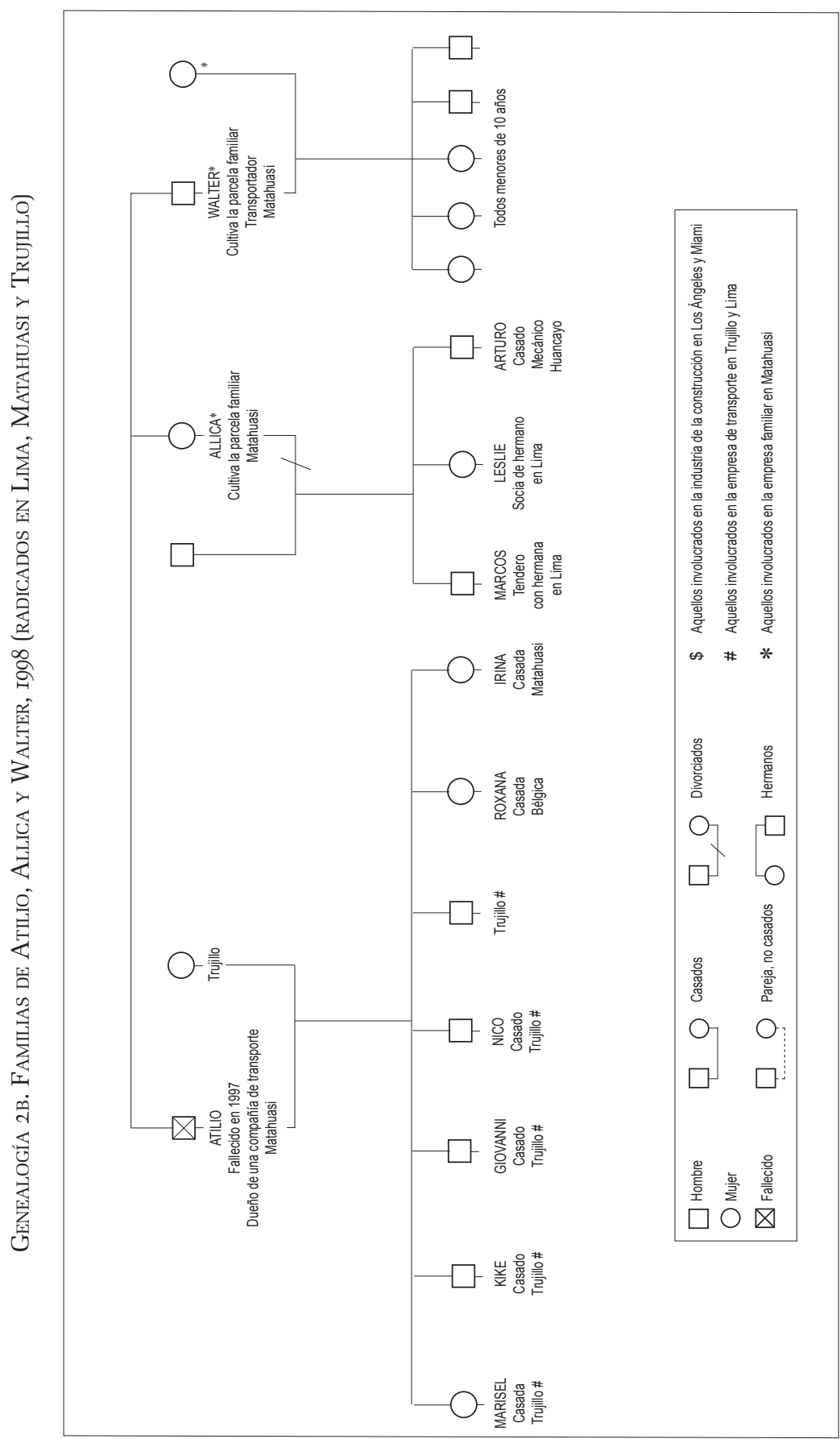




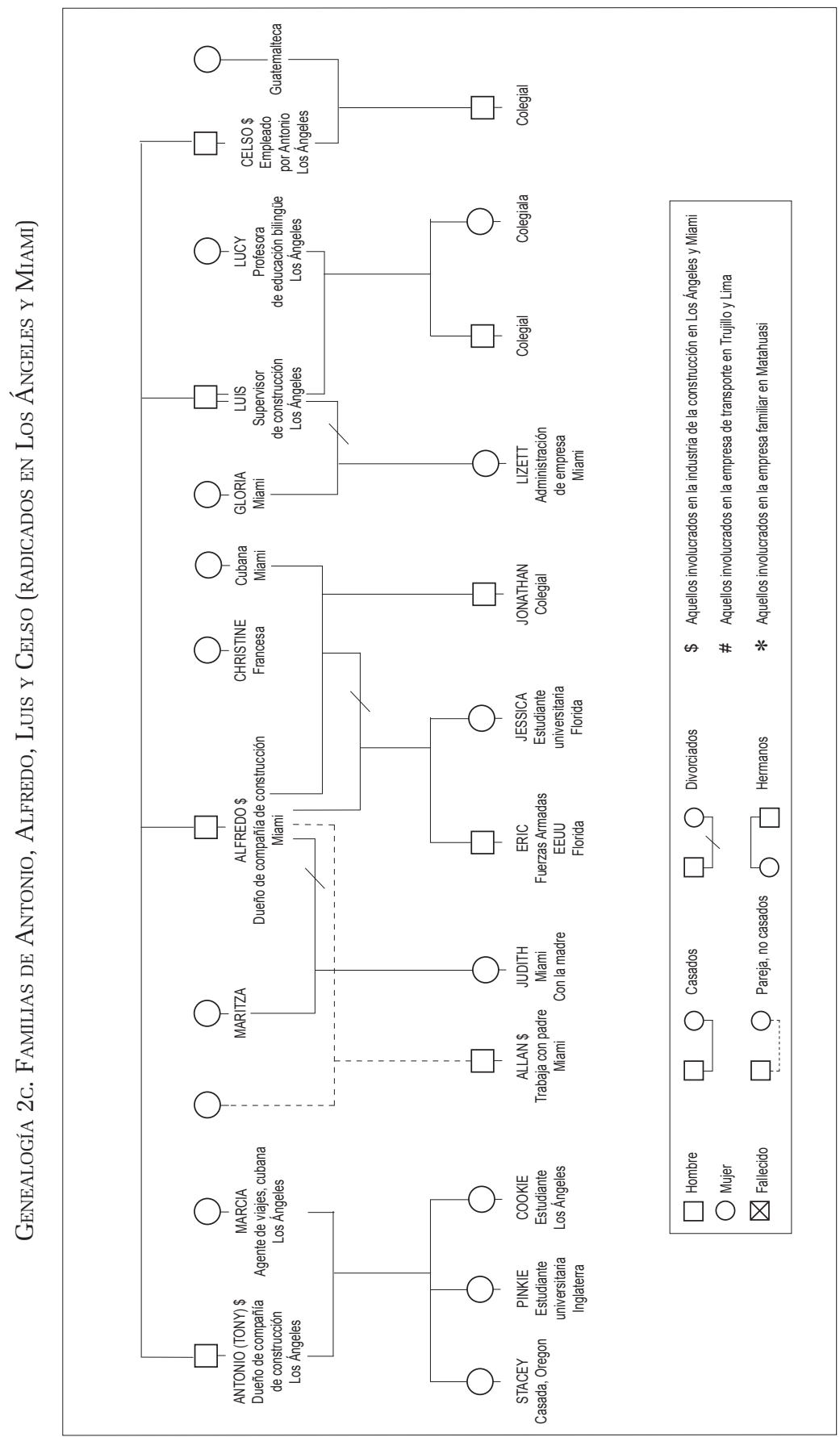


Varios antropólogos han subrayado la importancia de efectuar investigaciones genealógicas trigeneracionales para el estudio de las relaciones de parentesco y para identificar patrones diferenciales de carreras laborales, acceso a recursos y organización familiar ${ }^{5}$. Es claro que este método también es importante para comprender la emergencia

5. Para una discusión de estos puntos con ejemplos tomados de México, África y Java, véase Gabayet (I983), Den Ouden (I989) y Hüsken (I99I). de movimientos migratorios específicos y para delinear las cambiantes obligaciones del modo de vida para con el "hogar" y la reconfiguración de las solidaridades familiares "desde lejos". Los cambios que tienen lugar a lo largo del tiempo reflejan cambios en los tipos de trabajo, los niveles de ingreso, la educación, los patrones de matrimonio, el estatus social, los estilos de vida culturales y usos del lenguaje, y los sentimientos de "pertenencia". Si bien quizá sea posible rastrear estos hechos de manera general siguiendo el flujo de migrantes hasta sus lugares de destino y mediante la descripción de la medida en que mantienen contacto con sus conocidos que quedaron en "casa", un análisis que establezca mayores diferenciaciones requiere la comparación de diferentes tipos de personas y de sus situaciones familiares. Por supuesto que esto puede lograrse, en cierta medida, mediante la selección de una muestra de migrantes que represente diferentes características y circunstancias sociales, pero, en mi opinión, la referencia a un árbol genealógico común que abarque varias generaciones es una manera más satisfactoria de establecer comparaciones, pues permite explorar múltiples dimensiones sociales y culturales. Permite resaltar también un asunto central en la interpretación de las genealogías, a saber, el patrón de respuestas diferenciales que presentan diferentes ramas de la familia. El caso Jiménez pone esto de manifiesto de manera gráfica.

El declive y la inminente desintegración de la empresa original de la familia Jiménez, durante los últimos treinta años, tienen su origen, en gran parte, en la dinámica interna y en la diferenciación social de la familia. También se deben, en buena medida, a las fuerzas económicas y políticas más generales que intervinieron en Perú durante el mismo periodo.

A la empresa le iba razonablemente bien hasta los inicios de la década de 1980, momento en que resultó perfectamente claro que las políticas anteriores del gobierno, dirigidas a compensar 
las desigualdades en la tenencia de la tierra y la propiedad, inicialmente mediante una reforma agraria y la revitalización de los modos cooperativos de organización y, después, mediante el fomento a la privatización de las tierras comunitarias y al desarrollo de empresas regidas por el mercado, no lograron proporcionar prosperidad ni estabilidad a las zonas montañosas. El primer panorama tuvo como resultado el incremento de la presencia estatal en la configuración del desarrollo regional y local. El segundo se caracterizó por la disminución en la intervención directa del estado, lo que llevó a una fuerte reducción de los servicios gubernamentales relacionados con actividades tales como la extensión, el crédito y los aportes técnicos. Por tanto, ambas políticas contribuyeron al empeoramiento de las condiciones económicas en las zonas montañosas y en el país en general, y al crecimiento de la deuda nacional, agravada por la mala administración financiera y de otros campos. Esto incrementó la vulnerabilidad no sólo de los pobres en el campo y las ciudades, sino también de la clase media, incluidos los profesores y otros empleados del gobierno, los trabajadores independientes y los dueños y trabajadores de las industrias medianas y pequeñas.

Ante el aumento de las dificultades en el modo de vida y de la pobreza, que se concentraba principalmente en la población rural de las zonas montañosas y en los asentamientos urbanos pobres alrededor de las ciudades por todo Perú, emergieron diversas formas de descontento social. Finalmente, este adoptó la forma de una resistencia armada directa contra el estado, organizada en particular por Sendero Luminoso. Si bien en los primeros días la lucha entre este movimiento y el ejército peruano no afectó demasiado a la región del Mantaro, para fines de la década de 1980 y hasta su apogeo en 1992 sí tuvo enormes repercusiones en los habitantes del valle del Mantaro, de las zonas altas de pastoreo que lo rodean y de la ciudad de Huancayo.

No es sorprendente que estos eventos económicos y políticos perturbasen el funcionamiento de la empresa de Jiménez. Debieron afectar también las decisiones de miembros de la familia respecto a si volverían a Perú desde los Estados Unidos, o al pueblo desde Lima, o si, a raíz de esto, dejarían Matahuasi en busca de refugios más seguros. Hubo momentos en que miembros de la familia Jiménez que vivían en Matahuasi buscaron amparo en Lima. No era práctico mudarse a la cercana ciudad de Huancayo, dado que esta se había convertido en un foco de violencia y se estaba llenando 
de refugiados provenientes de las regiones montañosas del sur que la rodean, donde Sendero Luminoso estaba concentrado. En un intento por sacar de la zona a los rebeldes, el ejército peruano evacuó o expulsó a gran porcentaje de la población.

En estas condiciones era difícil obtener gasolina y muchas estaciones no pudieron conseguir o pagar los suministros, incluida la de la familia Jiménez. Además, los ingresos por la venta de gasolina bajaron debido a la reducción del movimiento en la zona y, sin duda, esto afectó al restaurante pegado a la estación. Había menos transeúntes y las familias o los grupos estaban menos dispuestos a alquilar el lugar para recepciones, puesto que se había vuelto peligroso reunirse en público, en especial de noche. A lo largo de esos años era crucial recibir el apoyo de un amplio espectro de residentes de Matahuasi, pero Jiménez y su familia no siempre pudieron contar con este, debido a continuas tensiones con la comunidad y las autoridades municipales. La emigración de los hijos de Jiménez fue también un factor crítico, dado que este hecho redujo la cantidad de mano de obra disponible para las distintas ramas de la empresa. Para I998, sólo tres de los hijos de Jiménez estaban viviendo en Matahuasi.

Los Jiménez pasaron de ser una familia unida en torno a una empresa múltiple en Matahuasi, a estar ahora dispersos por gran parte del centro y el sur de Perú, y en Estados Unidos y Bélgica. Esta red ampliamente extendida ha producido una significativa diferenciación social y cultural dentro de la familia, y algunos miembros y ramas mantienen más contacto que otros. Mientras que unas pocas familias aún conservan un interés en sus raíces matahuasinas, viajando de vuelta para tomar parte en las celebraciones del pueblo y en las fiestas del santo patrón, otros se han distanciado de estas influencias y han tratado de "reinventarse" como estadounidenses, escogiendo nombres anglófonos para sus hijos, mandándolos a instituciones educativas estadounidenses y construyendo estilos de vida domésticos en torno a los valores de ese país. Los miembros de la generación más vieja, la de los hijos de Jiménez, excepto Eric Hutton (véase la genealogía 2c) han reconciliado la cultura peruana y latina con los valores estadounidenses, haciendo una especie de malabarismo, al casarse con latinos residentes en los Estados Unidos y llevar un modo de vida mixto entre lo latino y lo estadounidense. Para los migrantes de primera generación la vida familiar era difícil y para las mujeres resultaba particularmente duro sobrevivir sin el apoyo cercano de 
sus familias de nacimiento. Por tanto, cada una de las nueras de Jiménez que se trasladaron a los Estados Unidos tuvo problemas maritales que llevaron al divorcio y a su regreso a Perú. Las hijas de Jiménez permanecieron en Perú.

A la empresa múltiple familiar con sede en Matahuasi le quedan pocos días de vida. Las interconexiones entre sus diversas ramas de actividad se han roto, está descapitalizada y, sin duda, se disolverá tras la muerte de Jiménez, cuando sus hijos intenten reclamar su herencia. Esto quizá beneficie a la rama de la familia que se dedica a la administración de empresas de transporte en Trujillo y Lima, que, en cualquier caso, continuará con sus propias actividades empresariales. Quienes se encuentran en los Estados Unidos están en vía de establecer una nueva vida social. Los hijos y nietos de Jiménez, de humildes orígenes en un pueblo en las montañas de Perú, están labrándose importantes nichos profesionales y de negocios, principalmente en los Estados Unidos, y, en consecuencia, es probable que se vuelvan menos "transnacionales" que antes. Ahora sus familias están firmemente asentadas en el mundo vital hispano-estadounidense, y parecen estar más seguros y sentirse más en casa cultural, social y emocionalmente allí, que lo que jamás podrían estarlo en Perú.

\section{Vidas transnacionales en Italia y PERú6}

A SEGUNDA DESCRIPCIÓN SE CENTRA EN LAS EXPERIENCIAS Y PRÁCTICAS
comunicativas de una madre que vive en un vecindario pobre
de Huancayo y de sus dos hijas que trabajan en Milán, Italia. El
por otro lado, también pone de relieve la manera en que las hijas reconfiguran las circunstancias vitales y los sueños de su madre. Los medios de comunicación, consistentes en llamadas telefónicas respaldadas por cartas con 
noticias enviadas de parte y parte, las mantienen en contacto cercano y les permiten comprometerse con las ideas, los sentimientos y los planes para el futuro de la otra. Durante estos intercambios se expresan y reafirman diversos modos culturales de practicar y comprender el bienestar de la familia y la solidaridad. El ejemplo es especialmente interesante puesto que demuestra que parientes cercanos separados por miles de kilómetros y que experimentan rutinas cotidianas muy diferentes pueden, no obstante, modelar mutuamente sus aspiraciones y nociones respecto a los mundos en que viven. Por supuesto, este tipo de proceso constituye el centro de las vidas transnacionales. Sólo una investigación etnográfica detallada, como la que aparece a continuación, puede revelar las profundidades ocultas de lo que Unni Wikan (I990) ha llamado "preocupaciones personales apremiantes".

\section{Camila y sus dos hijas en Milán}

C

OMO MENCiOnÉ ANTES, CAMIla Vive EN LAS AFUERAS DE LA CIUDAD DE Huancayo. Huyó a principios de la década de ig8o, junto con su esposo y sus cinco hijos, de Huancavelica hacia Huancayo, para escapar de la violencia en ascenso, provocada por Sendero Luminoso y el ejército. Camila finalmente se separó de su esposo, quien buscó refugio y trabajo en la selva amazónica. En esa época, una gran población de refugiados de Huancavelica y Ayacucho había construido albergues temporales en la periferia de la ciudad, donde los refugiados ocuparon un pedazo de tierra privada que no estaba siendo usada. Gradualmente ese espacio se transformó en un nuevo barrio que consiste en un mosaico de pequeñas casas de madera y adobe, y numerosas tiendas pequeñas y talleres, como montallantas, ferreterías, restaurantes, peluquerías, tiendas al detal, bares y puestos de mercado informales. Un gran porcentaje de los habitantes del barrio trabajaba como jornaleros en empresas de construcción, transporte y agricultura. No obstante, a pesar de toda esta actividad económica, la mayoría de los hogares seguía afrontando una vida precaria, en especial aquellas casas en que no había hombres adultos. 


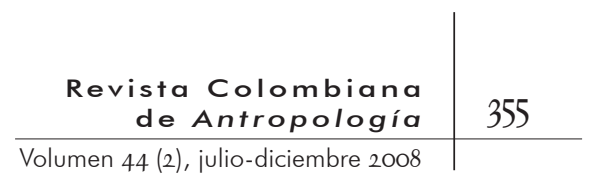

\section{Momentos críticos en la vida de las hijas en Milán}

Finalmente, las hijas de Camila, tras algunos aÑos DE ESTUdios y un periodo en el que trabajaron como empleadas del servicio doméstico en Lima, primero una y después la otra, aprovecharon la oportunidad de irse de Perú para buscar trabajo en Italia. La oportunidad se presentó por medio de Inés, cuñada de la madre, para quien habían trabajado como niñeras de sus hijos. Inés tiene muchos familiares en el extranjero y dos primos suyos se dedican al negocio de reclutar peruanos para que realicen trabajo doméstico en Europa. Ella aceptó ayudarlas para que se fueran del país y se les propuso que partieran hacia Italia. Inés y su esposo sirvieron de fiadores para el pago de los costos de los preparativos para la migración, ofreciendo su casa en Lima como garantía para el préstamo de seis mil dólares necesario para financiar el primer viaje. Una vez que la primera hija llegó a Italia y empezó a trabajar, pudo pagar la suma completa en tan sólo ocho meses, y, con base en esto, la segunda hija pudo unírsele. Las dos llegaron a su destino final, Milán, a través de una ruta por España y Francia. Así, en I997, ambas se habían establecido allí, trabajando como cuidadoras internas de ancianos.

Desde entonces, las hijas de Camila han intercambiado frecuentemente noticias con su madre, describiéndole las "experiencias inolvidables” por las que han pasado y asegurándole que estaban bien. El intercambio de cartas, sumado a la comunicación telefónica que mantienen con regularidad una vez a la semana, se convirtió en el mecanismo para mantenerse en contacto. Una parte del contenido de esos intercambios queda registrada en el extracto de una carta escrita por Rita, la hija mayor, en I998, que transcribimos a continuación:

Mamá, ya me he acostumbrado a estar aquí, aquí hay de todo. No falta nada: hay mucha comida y todo es delicioso. Ahora sólo tengo que limpiar dos salas de estar y las habitaciones y atender al joven Santiago [el hijo discapacitado de la familia italiana], quien me insulta cuando no le entiendo (pero después de tu útil consejo [relacionado con "ganarse su cariño"], ha estado más tranquilo). También estoy a cargo de lavar la ropa. Uso la lavadora y la ropa sale seca (algún día te voy a comprar una). Tengo que hacer todas estas cosas, pero como termino rápido, le ayudo a Karina (la cocinera). Se parece a ti y siempre me da la mejor comida (...). La señora 


\begin{abstract}
Marina (la dueña de la casa) ya me quiere porque dice que soy una buena trabajadora. Les conté que tú me enseñaste todo lo que sé y dijeron: “Tu madre debe ser una buena mujer". Por eso la señora me dio la ropa que te envié. Por eso quiero que les compres suéteres de alpaca y que me los mandes. También puedes comprarles unas artesanías peruanas bonitas (dile a Pedro [uno de los hijos] que las escoja) y mandármelas ${ }^{7}$.
\end{abstract}

7. Después, la madre efectivamente envió los suéteres de alpaca y las artesanías para regalar según lo pedido. También recibió su lavadora y muchos otros artículos para su casa. En I998, las hijas le enviaron mil quinientos dólares para que instalara una línea telefónica, y consignaron cinco mil quinientos dólares adicionales en una cuenta bancaria que habían abierto recientemente para ella; de éstos, dos mil dólares estaban destinados a cubrir los costos de comprar amuletos para la buena suerte para cada una de las hijas y los costos de los regalos para sus patrones. Por tanto, las cartas y llamadas telefónicas, que servían para reafirmar con regularidad sus lazos de solidaridad familiar y afecto, eran reforzadas con remesas de dinero relativamente grandes.
En respuesta a esta carta, Camila vuelve a recalcar la importancia de "ganarse el cariño" (debes ganarte su cariño) de su patrón y de su pareja al enfrentar circunstancias difíciles en la vida, en especial aquellas relacionadas con el hecho de ser un migrante. También menciona la necesidad de obtener la ayuda de los patrones en la lucha para legalizar su trabajo y conseguir el estatus de residente. En otras

ocasiones, ofrece consejos respecto a cómo actuar frente a las relaciones sociales y a los novios. En un caso particular, cuando una de las hijas alabó las virtudes de su nuevo novio, un "apuesto italiano", la madre decide probar la conveniencia de esta relación mediante la adivinación, lanzando granos de maíz. A partir de esto concluye que salir con él no sería una muy buena idea. Por tanto, llama por teléfono a su hija para ordenarle que "lo deje" de inmediato. En otra ocasión, afirma, de nuevo con base en la adivinación, que la hija mayor debería presentar en ese momento los documentos para legalizar su residencia; enfatiza que es un momento adecuado para hacerlo, pero sugiere que la otra hija debería esperar y presentar sus documentos mucho después. De no ser así, las cosas podrían salir mal.

Estos fragmentos de vida social, comunicados internacionalmente vía cartas y teléfono, representan una instantánea del continuo flujo bidireccional de información, ideas, valores, concepciones, imágenes, discursos, influencias y creencias que tiene lugar entre los migrantes y sus parientes y amigos en casa. Este caso proporciona una interesante comprensión de este proceso. En primer lugar, resalta el grado en que prácticas culturales "de casa" pueden penetrar las vidas cotidianas de migrantes distantes 
y así moldear sus decisiones y relaciones sociales. Segundo, indica el modo en que la información y los consejos que los migrantes reciben de sus comunidades "en casa" y de las redes de migrantes "paisanos" pueden configurarsus sus percepciones respecto a la sociedad que los recibe e incluso su actitud hacia personas determinadas. Y, por supuesto, también puede decirse lo contrario, dada la influencia que tienen los migrantes sobre sus familiares y amigos "en casa". Si bien nada de esto es específico de las situaciones transnacionales, dado que se han hecho observaciones similares respecto a la migración dentro de países, la manera como estos hechos operan en el contexto transnacional sigue siendo un gran reto para la investigación. De hecho, puede afirmarse que el advenimiento y la diseminación a lo largo del planeta de nuevos modos de comunicación de alta velocidad puede llegar a fortalecer, en vez de disolver, identidades basadas en el reconocimiento local, étnico y nacional. De esta manera, los beneficios de las redes y la comunicación transnacionales pueden ser empleados para conseguir objetivos más provincianos.

Una repercusión adicional es que, del mismo modo que las familias y comunidades gastan mucho tiempo y hacen grandes esfuerzos por mantener conexiones con familiares y amigos en el extranjero, también el estado peruano está sumamente interesado en mantener relaciones políticas y económicas con la diáspora de sus nacionales. En este momento Perú tiene una de las más altas tasas de emigración de Latinoamérica (ONU, 2002; Altamirano, 2000). Recientemente, el Ministerio de Relaciones Exteriores, por medio de la red de consulados peruanos en todo el mundo, ha puesto en práctica políticas dirigidas a extender su alcance a la diáspora para alentar a sus nacionales a invertir parte de sus considerables recursos financieros y sociales en empresas conjuntas de desarrollo en Perú ${ }^{8}$.

Esto indica la importancia de llevar a cabo estudios detallados de los tipos de prácticas comunicativas y de los contenidos

8. Esto puede compararse con los intentos de México por desarrollar programas efectivos de ciudadanía dirigidos a fomentar asociaciones empresariales con comerciantes de origen mexicano asentados en los Estados Unidos. Durante su periodo como gobernador de Guanajuato, Vicente Fox lideró el programa Mi comunidad (Byrnes, 2003); hay iniciativas similares, como Tres por uno en el estado de Zacatecas, que iguala la suma de las remesas con subvenciones del gobierno, y en Guerrero los migrantes pueden solicitar apoyo.

simbólicos empleados por los migrantes para mantener contactos en casa y para procesar sus experiencias cotidianas. Las investigaciones previas acerca de la migración latinoamericana, tanto 
la rural-urbana como la transnacional, han documentado la manera en que los migrantes en entornos externos mantienen las conexiones con sus comunidades de origen, al mismo tiempo que forjan nuevas clases de vínculos individuales o colectivos en sus ubicaciones "receptoras". Por ejemplo, hay muchos estudios que resaltan la importancia de las relaciones de compadrazgo -parentesco ritual-; de los esfuerzos cooperativos grupales -que implican la organización de faenas o fiestas de trabajo colectivo-; del patrocinio de fiestas, y de la participación en asociaciones de "paisanos" -que en Perú se denominan clubes de migrantes del pueblo o de la región-, en fraternidades religiosas y en festividades públicas. Estas prácticas siguen siendo importantes para comprender la organización social de la translocalidad, pero hoy en día están respaldadas por nuevas formas de comunicación mediática, entablada desde ambos lados de la cadena migratoria, tales como los correos electrónicos y otras formas de comunicación por internet, las llamadas mediante teléfono satelital, la circulación de fotografías y la elaboración y el envío de videos. A esto debemos añadir el contacto con programas de radio y televisión, en especial aquellos que examinan aspectos cercanos a las situaciones y experiencias de los migrantes.

Por tanto, debemos conocer la manera exacta en que estas prácticas ayudan a moldear y mantener las diversas conexiones sociales, políticas, económicas y emocionales entre los migrantes y sus familiares y amigos en casa. ¿Qué recuerdos, sentimientos e ideas respecto al "progreso" y la "modernidad", por ejemplo, se comunican y refuerzan? ¿Qué compromisos culturales, visiones del mundo y relaciones sociales específicas se presentan y reafirman en la situación del migrante mediante estas comunicaciones mediáticas? Y, ¿cómo se articulan entre sí las "viejas” y las "nuevas" prácticas comunicativas? Para responder a estas preguntas, y a otras relacionadas, necesitamos establecer maneras más efectivas de construir etnografías de migración multisituadas.

La parte final del artículo amplía estas observaciones y plantea la pregunta por la investigación del significado de las remesas para el mantenimiento de las relaciones translocales y su impacto en los procesos de desarrollo local y regional. Una vez más, el razonamiento hace uso de datos extraídos del centro de Perú. 


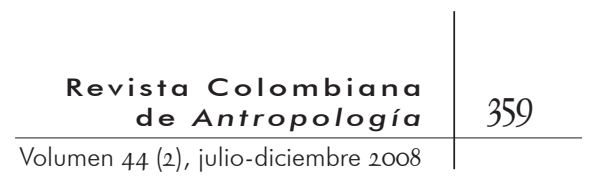

EL CARÁCter de CONSTRUCCIÓN SOCIAL DE LAS REMESAS

ARIAS PUBLICACIONES RECIENTES HAN PLANTEADO LA IMPORTANCIA DE
extender la noción de "remesas", de tal manera que abarque
los componentes sociales y culturales incluidos en las transferencias de dinero, capital o bienes que los migrantes hacen a sus parientes y amigos en sus comunidades de origen (Levitt, 1996; Goldring, 2004; S $\phi r e n s e n, ~ 2004,2005)$. Un segundo argumento es que el concepto de remesas no debería limitarse a considerarlas como un proceso unidireccional, puesto que es obvio que también debemos prestar atención a los flujos de bienes, recursos y artículos socioculturales que llegan a migrantes individuales y a sus familias desde su lugar de origen. El funcionamiento de los flujos de remesas es en esencia un proceso dinámico bidireccional. Es más, en la idea misma de que las familias y las comunidades se envíen bienes está ya supuesta la manera en que esas transferencias se encuadran simbólicamente y se efectúan en la práctica. Un tercer punto crucial se relaciona con la distinción y oposición entre transferencias individuales y familiares, y otras de carácter más colectivo. Estas últimas, por supuesto, suponen la recolección y donación organizadas de fondos, materiales, tecnologías y consejos basados en formas especializadas de conocimiento. Tal como lo mostré en el ejemplo de la región del Mantaro, tales empresas colectivas han sido de una importancia decisiva para el apoyo a proyectos de desarrollo local en el lugar de origen, y muchas de ellas fueron planificadas y fundadas por clubes de migrantes y asociaciones regionales debidamente avaladas.

En ocasiones, las entidades gubernamentales de desarrollo han canalizado los ahorros y el capital de inversión, acumulados por migrantes individuales o por organizaciones, mediante un sistema de equiparación de fondos. Además, los bancos y las instituciones financieras cambiarias han presionado para que se creen modos más eficientes de transferir los fondos de los migrantes, con el fin de disminuir la dependencia de intermediarios particulares, quienes tienden a cobrar tarifas altas. No obstante, el proceso de hacer estas transacciones mucho más transparentes y justas también tiene algunas desventajas para los propios migrantes, puesto que la insistencia en una mayor transparencia y un mayor control, naturalmente, le da a los gobiernos más influencia en la 
manera en que estos recursos financieros deben ser canalizados y empleados ${ }^{9}$. Estos asuntos son mucho más críticos para los migrantes internacionales debido a la distancia y a los problemas que plantean las fronteras internacionales.

En la sección del artículo dedicada al Mantaro presenté unas cuantas instantáneas que ilustran el flujo de remesas de diversos tipos entre los migrantes y sus familias, y entre las asociaciones de migrantes y las autoridades de los pueblos $\mathrm{u}$ organizaciones locales. Si bien tales flujos son comunes en todo Perú para el caso de todo tipo de migrantes, suelen escasear los detalles acerca de su modo, cantidad y frecuencia. Durante siglos la región andina ha sido escenario de un constante desplazamiento de personas entre diferentes zonas ecológicas y lugares de concentración de empleos. La permanencia de estas en sus lugares de llegada ha variado dependiendo de las circunstancias regionales y del tipo de actividad que desarrollan -agrícola, pastoril, minera o comercial-. Algunos desplazamientos llevaron finalmente al reasentamiento de familias e incluso de comunidades enteras, reconfigurando así el panorama social ${ }^{10}$. Estos procesos se agudizaron en el siglo veinte, a medida que se aceleró la urbanización.

9. Estos problemas recientemente han sido fuente de gran preocupación para varias entidades internacionales de desarrollo, puesto que durante la última década se elevaron astronómicamente las transferencias internacionales de migrantes. Tan sólo en 2004 hubo un movimiento de más de 45 mil millones de dólares desde el resto del mundo hacia Latinoamérica y el Caribe, repartidos en cantidades relativamente pequeñas de entre doscientos a trescientos dólares mensuales. La mayoría de las veces, los trabajadores envían sus remesas mediante empresas de transferencias de dinero o agentes locales del vecindario, y no mediante bancos. Esto hace que sea difícil incluir estos flujos en las estadísticas financieras formales. Para una discusión completa de las dimensiones económicas y sociales de las remesas de los migrantes, véase De Vasconcelos (2005).

IO. Thierry Saignes (I995) documenta la importancia central que tuvieron la migración interna, el reasentamiento y el cambio social durante el siglo diecisiete en el sur de los Andes, y subraya los fuertes lazos que mantuvieron los migrantes con sus lugares de origen.

exigió que devolviesen los costos administrativos y de transporte a los intermediarios en Lima que hicieron los preparativos para lógica sobre Perú, que contiene datos útiles acerca del entrelazamiento de los modos de vida rurales-urbanos y locales-globales, constituye una útil fuente de información. Consideremos por un momento el caso de Camila y sus dos hijas en Italia. Este ejemplo llama la atención sobre varios componentes adicionales. En primer lugar, el hecho de que se trate de mujeres solteras no es excepcional en lo más mínimo, puesto que recientemente se ha incrementado notablemente el número de mujeres solteras que migran para conseguir trabajo en Europa. Aun cuando se les

La extensa literatura antropo-

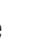

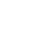


su viaje y para la entrada ilegal a Italia, entre las dos, no sólo lograron pagar la deuda, sino que también ahorraron un total de 35.00o dólares en sólo cuatro años. Una de las principales razones para esto es que, como cuidadoras de ancianos, recibían alimentación y alojamiento gratis, y trabajaban seis días a la semana. Así, con esmero y mucho esfuerzo, lograron acumular unos ahorros considerables. Con el tiempo estuvieron en posición de enviarle a su madre cerca de trescientos dólares cada mes, y en 2000 financiaron, con una cantidad de 30.000 dólares, la construcción de una nueva casa para su madre. Esto hizo que la vivienda de la madre estuviese por encima de las demás en su vecindario e hizo de ella el centro y objeto de envidias y brujería. Por supuesto, al enviarle estas sumas, las hijas estuvieron muy pendientes de los gastos de la madre y le señalaron inversiones específicas.

Las dos hijas estaban muy comprometidas con mejorar las condiciones de vida de su familia en Huancayo. Como ellas mismas lo afirman: “Tenemos que progresar. Queremos que nuestros hermanos se vuelvan profesionales y logren mejores posiciones sociales. Deseamos lo mejor para ellos”. Como la mayoría de los otros hogares en Huancayo y en los pueblos del Mantaro, Camila usaba una porción de la remesa mensual que recibía para suplir sus necesidades de consumo; esto es, para comprar comida, pagar por la educación de sus otros hijos y comprar ropa. El resto del dinero se destinaba a inversiones importantes que beneficiarían a las hijas a su regreso de Italia.

En contraste con este caso familiar específico, Tamagno (2003: 3I5-30) ofrece una descripción de la manera como el alcalde de Huachac, un distrito rural cercano a Huancayo con un alto nivel de emigración, coordinó que diferentes grupos de personas de su distrito que vivían y trabajaban en Milán (Italia), Los Ángeles (Estados Unidos), y Lima (Perú), se comprometieran a recaudar fondos para obras públicas. En agosto de 2000, los grupos visitaron el pueblo para participar en las celebraciones anuales del santo patrón del distrito -santo Domingo de Guzmán-. El alcalde invitó a los líderes de cada grupo de migrantes a que asistieran a una reunión especial en la municipalidad para discutir ideas sobre proyectos de desarrollo local y para sugerir que cada grupo se hiciera responsable de proyectos específicos. Había gran interés y muchos de los líderes y "jefes" importantes de los tres grupos de migrantes llegaron con ideas acerca de proyectos prioritarios. Sin embargo, al plantear sus prioridades, cada uno dejó ver cuáles eran sus ideas sobre lo 
que implicaba el "desarrollo". Todos mostraron interés en mantener vínculos y fortalecer la solidaridad interna de los clubes de migrantes, pero, en definitiva, sus ideas acerca de los proyectos locales discrepaban asombrosamente. El grupo de Italia optaba por financiar la construcción de un centro de telecomunicaciones de última tecnología en Huachac, con una central telefónica y cubículos de internet para uso público. Consideraban que esta era una manera práctica de fortalecer sus lazos con la familia y los amigos en casa, de modo que fuese más fácil para estos hacer llamadas o enviar mensajes de correo electrónico desde el pueblo. Los "huachaquinos" que vivían en Estados Unidos escogieron la idea de construir un centro comercial, a imitación de alguna clase de mall o galería de tiendas y centros de servicio estadounidense, que incluyese restaurantes, tiendas y papelerías. Finalmente, los de Lima propusieron un instituto superior que llenase el gran vacío en la oferta de cursos educativos y de entrenamiento vocacional para los jóvenes de la municipalidad. Según este grupo, esto prepararía mejor a los jóvenes para que pudiesen obtener trabajos calificados y profesionales; la educación sería el medio principal para lograr movilidad social, tal como lo había sido para ellos en las décadas de 1960 y I970. Por supuesto que, al afirmar esto, decidieron pasar por alto el hecho de que, en las de 1980 y I99o, la mayoría de los profesionales en Perú enfrentó una caída notoria de sus ingresos y poder adquisitivo.

Mediante el análisis de estas narrativas de desarrollo opuestas, Tamagno saca a la luz la imagen que cada grupo tiene de sí mismo y la manera en que conciben las necesidades del pueblo. Al final de la reunión, se le pidió a cada grupo de migrantes que se comprometiera a recolectar una determinada suma de dinero, destinada a un proyecto de desarrollo específico. Después, se dejó constancia de estas propuestas en el Libro del oro -el libro de contabilidad financiera del pueblo- como un mecanismo para sellar los acuerdos. Unas cincuenta personas de fuera del pueblo -de Lima, España, Italia y Estados Unidos- asistieron a esta reunión como testigos de los compromisos establecidos. Además, Andrés, un importante líder del grupo de los residentes en Italia, declaró ante todos que ya había recaudado, entre parientes y amigos en Italia, unos tres mil dólares como contribución para los costos de la fiesta de ese año y que él mismo había donado siete mil quinientos dólares adicionales. 


\section{Flujos de remesas entre Cajatambo y Lima}

A CONTINUACIÓN EXAMINARÉ UN CASO DIFERENTE RELACIONADO CON REMESAS en un contexto de migración interna (Rodríguez, 1994). Este estudio es poco común en la medida en que identifica y mide los tipos, las cantidades y la frecuencia del flujo bidireccional de remesas entre una región central andina y la ciudad de Lima y El Callao. La región montañosa a la que nos referimos es Cajatambo, localizada al noreste de Lima. La zona es predominantemente un área de producción ganadera y lechera, combinada con el cultivo de trigo, maíz, papas y otros vegetales. Queda a unas cuatro horas de Lima, viajando por tierra.

En comparación con la región del Mantaro, la economía de esta área está mucho menos diversificada, es menos dinámica y los niveles educativos también son más bajos. Hay una migración permanente de hombres jóvenes -en su mayoría- que viajan a Lima en busca de trabajo y una mejor educación. En una muestra de 6I3 personas asociadas al Club Juventud Cajatambo, se estableció que 63\% vivían en el cono norte de Lima en medio de varios asentamientos urbanos de invasión -a menudo denominados asentamientos populares- que originalmente fueron fundados a mediados de la década de I980 mediante la ocupación de tierras.

Entre I989 y I990 se llevaron a cabo investigaciones para delinear y analizar los flujos económicos, sociales y culturales entre la región de Cajatambo y los asentamientos urbanos cercanos a Lima en que viven los migrantes de Cajatambo. Se seleccionaron unos treinta y cinco hogares en las afueras del área metropolitana para realizar entrevistas detalladas, y se examinaron varias fuentes documentales para obtener información sobre el flujo de mercancías, paquetes y cartas. También se entrevistó a importantes negociantes dedicados a la comercialización de productos ganaderos y agrícolas. Finalmente, se estudiaron los mensajes y la información emitida por un programa especial de radio "de difusión” -programa radial Amanecer cajatambino-, dirigido a personas de Cajatambo.

Los principales resultados de las entrevistas en hogares fueron los siguientes: las familias en Cajatambo enviaban productos alimenticios -o lo que el autor llama "productos de subsistencia"consistentes en papas, maíz, carne y productos lácteos a sus fa- 
miliares en Lima; estos últimos le devolvían el favor a sus familias suministrándoles variedad de artículos alimenticios procesados, medicamentos y ropa. El 68,6\% de la muestra dijo haber recibido productos de Cajatambo y 74,3\% dijo haber enviado artículos a casa. En ambos casos se trataba de artículos para consumo directo. La información acerca de la frecuencia de los flujos indicó que $62,5 \%$ de los hogares enviaba artículos cada mes -algunos incluso una vez por semana-,8,3\% lo hacía cada tres meses, y el resto (29,2\%) sólo hacía envíos para la época de las fiestas del santo patrón y para las celebraciones de año nuevo.

En algunos casos, las familias enviaban gran cantidad de comestibles con regularidad. Por ejemplo, los miembros de un hogar particularmente grande con sede en Cajatambo, con varios hijos e hijas que vivían en Lima, les enviaban una vez al mes un paquete gigantesco con unos 50 kilogramos de comida compuestos por $6 \mathrm{~kg}$ de queso, I kg de mantequilla, medio $\mathrm{kg}$ de manjarblanco, 8 cuyes, medio cordero, de 4 a $5 \mathrm{~kg}$ de carne de res -cuando podían conseguirla-, $25 \mathrm{~kg}$ de papa, de 6 a $7 \mathrm{~kg}$ de mazorca, unos $3 \mathrm{~kg}$ de harina de trigo y otros tantos de harina de maíz. A pesar de esto, el promedio para la muestra se calculó en cerca de $20 \mathrm{~kg}$, compuestos de papas, maíz, trigo, fríjoles, carne seca y queso.

Rodríguez (I994) observa que los migrantes tenían en muy alta estima estos alimentos por razones culturales, puesto que formaban parte de la cocina preferida en la región de Cajatambo. No obstante, varios entrevistados señalaron también el hecho de que esta era una manera de ahorrar en gastos, dado que los precios de algunos artículos importados a la región eran, de hecho, menores en Cajatambo que en Lima ${ }^{11}$ Aunque los familiares de Cajatambo ocasionalmente visitaban los hogares en Lima, y viceversa, el estudio revela que buena parte del transporte de mercancías se organizaba en grandes cantidades. Es decir que, para reducir los costos y acelerar el transporte,

II. Por ejemplo, entre 1987 y I988, la municipalidad de Cajatambo ofreció precios más bajos subsidiados para el azúcar y el arroz producidos en la zona costera y transportados a la zona montañosa. las familias cooperaban preparando paquetes entre varias y los encomendaban a microbuses que con regularidad cubren la ruta hacia Lima y de vuelta. En Perú es una práctica normal que estos buses lleven paquetes y encomiendas para entregas especiales. El registro de mercancías transportadas a Lima entre 1988 y 1989 de la Empresa Municipal de Transportes Cajatambo indicó que la cantidad mensual de 
paquetes -canastas familiares- oscilaba entre veinte y cincuenta, con un peso de cerca de $20 \mathrm{~kg}$ por paquete.

Con base en estas cifras y en un estimado de las necesidades básicas de consumo de alimentos de las familias de migrantes en Lima, Rodríguez concluye que estas remesas satisfacían cerca de 50\% de las necesidades para la subsistencia de los migrantes. Si bien esta cifra puede parecer alta, vale la pena recordar que el estudio se efectuó durante un periodo crítico en el que Sendero Luminoso aún se encontraba activo en los asentamientos urbanos más pobres de Lima y en las zonas montañosas cercanas ${ }^{12}$. También fue una época de agudización de la crisis económica, en la que las industrias se deshicieron de muchos trabajadores, los salarios reales cayeron abruptamente y el porcentaje de hogares limeños que vivían en situación de pobreza crónica aumentó de 5\%, entre I985 y I986, a 20\% en I990 (Ypeij, 2000: 26) ${ }^{13}$ Por tanto, el alto nivel de remesas de alimentos provenientes del campo parece ser consecuente con la necesidad urgente de suplir el modo de vida de los hogares de migrantes asentados en la ciudad.

Así como los hogares urbanos recibían ayuda consistente en comestibles de sus familias en casa, también los migrantes les enviaban productos a estas. Generalmente se trataba de productos que en Cajatambo tenían altos precios, eran escasos o no estaban disponibles. La mitad de quienes hicieron envíos afirmó que consistían en víveres y ropa; los demás también incluyeron medicinas, insumos agrícolas, como fertilizantes y pesticidas, y dinero. Con respecto a la frecuencia de los envíos, esta era mucho menor: 30,8\% dijo que enviaba artículos por lo menos una vez al mes, I9,2\% cada tres meses, 42,3\% lo hacía "de vez en cuando" y 7,7\% no lo sabía con certeza. A diferencia de los pro-

I2. Rodríguez registra que durante su estudio, en febrero de I990, Sendero Luminoso atacó en Cajatambo dos vehículos, lo que causó la muerte de cinco policías y tres campesinos.

I3. En agosto de I990, el presidente Fujimori, que acababa de ser elegido, puso en marcha un paquete de duras medidas económicas diseñadas para enfrentar el rápido deterioro de la economía. Durante este periodo, Annelou Ypeii (2000) realizó en Lima investigaciones de campo sobre empresarios de pequeña escala (hombres y mujeres) para documentar la manera como respondieron a estas condiciones que tendían a empeorar. Concluyó que, si bien en muchos casos sus ingresos se vieron reducidos sustancialmente, con frecuencia fueron capaces de mantener sus negocios, ideando maneras de complementar las ganancias del hogar. Había dos maneras de lograrlo: la primera implicaba que los miembros de la familia desempleados (mujeres casadas, niños y pensionados) buscasen maneras adicionales de ganarse la vida, y la segunda suponía bajar el precio de costo por la venta de sus productos mediante la reducción de los costos por mano de obra. Un modo de hacer esto consistía en reemplazar trabajadores pagos con el trabajo gratuito de familiares. Con frecuencia, los trabajadores familiares eran contratados mediante conexiones de parentesco en su pueblo de origen y eran recibidos como aprendices (ayudantes) (2000: I4O-I, I2O-3). 
ductos que eran enviados desde Cajatambo, los artículos enviados desde Lima por lo general habían sido adquiridos en el comercio; y aun cuando se tratase de productos hechos o cultivados en casa, lo más probable es que sus ingredientes o materias primas hubiesen sido comprados. Por tanto, la imagen que se dibuja para inicios de la década de 1990 es que cerca de tres cuartos de los hogares urbanos con raíces en Cajatambo enviaban cantidades considerables de comestibles procesados y de otros artículos de consumo a miembros de su familia en Cajatambo ${ }^{14}$.

En lo relativo a las remesas de dinero tenía lugar un proceso bidireccional similar: $22,9 \%$ de la muestra total de hogares reportó que habitualmente enviaba a Cajatambo giros de dinero; de estos, la mitad afirmó enviar cantidades fijas mensual o bimensualmente, mientras que los demás afirmaron enviar dinero sólo de vez en cuando. La mayoría de estos pagos se hicieron a los padres o suegros $(62,5 \%)$ y el resto a hijos que vivían en las zonas montañosas. No obstante, durante el estudio se encontró que era difícil establecer exactamente qué cantidades fueron transferidas, puesto que resultó manifiesto que existía una amplia variedad de maneras de enviar dinero, tanto formales como informales. Con frecuencia se enviaban sumas según las necesidades por medio de familiares o amigos, pero era imposible calcular con cualquier asomo de precisión las cantidades ${ }^{15}$. Al igual que en el caso de las mercancías enviadas, el periodo en que había más transferencias de efectivo coincidía con la época de las fiestas y de las celebra-

I4. Infortunadamente, debido a la grandísima heterogeneidad de los productos comestibles procesados y de consumo que eran empacados para su entrega en Cajatambo, el estudio no pudo discriminar el volumen y los contenidos de los cargamentos.

I5. Los estimados de transferencias de dinero a través de la Empresa Municipal de Transportes Cajatambo fueron muy bajos. Rodríguez calcula que en el caso de treinta y cinco hogares, durante el periodo de mayo a diciembre de 1998 se enviaron de Lima a Cajatambo un total de 375,5 dólares, mientras que de Cajatambo a Lima sólo se enviaron 132,6 dólares. Esto tiene sentido, puesto que es más probable que los hogares de los migrantes tengan mayor acceso a entradas habituales de dinero, que lo contrario. ciones de año nuevo.

Es más, la composición y el volumen precisos de los productos y el efectivo enviados variaban dependiendo de las prioridades estratégicas de las familias en cuestión. Por ejemplo, si un familiar cercano necesitaba atención médica urgente, si los niños requerían uniformes, libros y útiles para el colegio, o si el padre o la madre necesitaban apoyo para cumplir con sus obligaciones como patrocinadores de algún evento social o religioso, entonces lo habitual era que los miembros de la familia y de los hogares asentados en la 
ciudad hicieran todo lo posible para responder a las necesidades. Por otro lado, cambios dramáticos en la economía nacional, tales como la inflación galopante que creció a una tasa de 30\% mensual en 1989 o las medidas políticas recientemente impuestas que vinieron a continuación, conocidas como el "Fujishock", tuvieron un claro impacto tanto en los modos de vida rurales como en los urbanos y en sus interconexiones. El presidente Fujimori llegó a un acuerdo con el Fondo Monetario Internacional, que implicaba poner fin a los subsidios de los productos de subsistencia, incrementar los impuestos y una inimaginable alza, de la noche a la mañana, de los precios de la gasolina en $3.000 \%$, que tuvo repercusiones en el precio del transporte público, la electricidad y los medicamentos. Incluso las medidas más positivas, como distribuir bonos extraordinarios e incrementar el salario mínimo legal en 400\%, no lograron aliviar el empobrecimiento de gran parte de la población (Ypeij, 2000: 27). En palabras de un hombre que tenía una pequeña zapatería:

El día del paquetazo (el "Fujishock") no tenía muchas existencias. Sólo tenía tres docenas de zapatos. Tampoco tenía comida. Logramos sobrevivir porque mi primo -quien comparte la misma casa- acababa de regresar de las montañas y él tenía papas, granos y ese tipo de cosas. Eso fue lo que más nos ayudó. Fue suficiente para superar el paquetazo. Gastamos muy poco dinero. Hice todos los zapatos para vender que pude. Acumulé deudas y usé el dinero para comprar comida. Cuando el paquetazo terminó, sólo tenía deudas, no tenía materiales (para producir) en la casa, no tenía nada. No gané nada durante dos o tres meses. Acabo de vender la zapatería porque pedí dinero prestado a amigos y lo usé para comprar artículos para comerciar (Ypeij, 2000: 28).

Dados estos caprichosos cambios en la economía y la política, muchos hogares pobres, e incluso de ingresos medios, quedaron en una situación de extrema vulnerabilidad ante la pobreza crónica y las enfermedades. Sólo manteniendo estrechos vínculos sociales con parientes, paisanos y amigos en la ciudad y en el campo pueden sortear la situación. El componente decisivo de tales redes se halla en el patrón de intercambios habituales de mercancías, servicios, información, ideas y obligaciones sociales que se desarrolla entre las partes involucradas. Como lo he demostrado en varias partes de este artículo, tales redes no se componen simplemente de conjuntos individuales de lazos. Con 
frecuencia implican también actividades grupales y relaciones asociativas que se basan en valores o en diversos tipos de prácticas sociales preexistentes y acordadas.

Por todas las razones mencionadas, el estudio de la naturaleza e importancia de las remesas requiere una comprensión profunda de los flujos, los significados, las prácticas organizativas y los mundos vitales de los actores migrantes y no migrantes. Debemos examinar también cómo los arreglos en los modos de vida son moldeados y reconfigurados por los diversos contextos en los que se presentan. Por tanto, es importante no abstraer el caso de las remesas del resto del tejido social. Los flujos de mercancías particulares y de dinero se enmarcan en los valores y significados que se les asignan y en el carácter de sus transacciones específicas (Long y Villareal, I998). Por eso debemos entrar de nuevo en el difícil terreno que rodea al problema de la confrontación entre los valores "mercantiles" y los valores "no mercantiles" (Long, I997: 226-44; 200I). Si bien los economistas quizá seguirán insistiendo en que las transferencias de bienes y de dinero se comprenden mejor en relación con los principios del mercado y los precios de las mercancías, los científicos sociales deben mantener su posición y sostener que la comprensión de las remesas, en el contexto de la migración y de los modos de vida múltiples, requiere captar adecuadamente asuntos de raigambre social y cultural.

\section{Bibliografía}

Altamirano, T. 1984a. "Regional commitment among migrants in Lima". En N. Long y B. Roberts. Miners, peasants and entrepreneurs. Cambridge University Press. Cambridge. 1984b. Presencia andina en Lima metropolitana: un estudio sobre migrantes y clubes de provincianos. Pontificia Universidad Católica del Perú. Lima.

-2003. "From country to city: Internal migration". ReVista: Harvard Review of Latin America. Cityscapes. Latin America and Beyond. Edición especial: invierno.

Altamirano, T. y L. Hirabayashi (eds.). 1997. Migrants, regional identities and Latin American cities. American Anthropological Association. Society for Latin American Anthropology. 
Arce, A. y N. Long (eds.). 2000. Anthropology, development and modernities: Exploring discourses, counter-tendencies and violence. Routledge. Londres y Nueva York.

BERG, U. D. 200I. “'Locating Matahuasi': The politics of place and mobility in Andean Peru”. Tesis de maestría. Instituto de Antropología. Universidad de Copenhagen.

Brynes, D. M. 2003. Driving the State: Families and public policy in Central Mexico. Cornell University Press. Ithaca y Londres.

DANDLER, J. 1987. "Diversificación, procesos de trabajo y movilidad espacial en los valles y serranías de Cochabamba”. En La participación indígena en los mercados sur-andinos. CERES. Cochabamba.

Dandler, J. y Carmen Medeiros. i988. “Temporary migration from Cochabamba, Bolivia to Argentina: Patterns and impact in sending areas". En P. Pessar (ed.). When borders don't divide: Labor migration and refugee movements in the Americas. Center for Migration Studies. Nueva York.

De Vries, P. y J. M. Gilvinio. 200I. "Debating property: Property relations and the cultural construction of community in Usibamba, Central Andes”. En Land and sustainable livelihood in Latin America. Royal Tropical Institute, KIT Publishers, Iberoamericana/Vervuert Verlag. Amsterdam y Frankfurt.

De VASCONCELOS, P. 2005. "Improving the development impact of remittances". Artículo presentado en la reunión de expertos de las Naciones Unidas sobre migración internacional y desarrollo. Nueva York, del 6 al 8 de julio.

Den OudEn, J. H. B. I989. "A three generation perspective: Its importance for ethnographic research in development studies. Case studies from Cameroon and Benin". Artículo presentado en la 88 reunión anual de la American Anthropological Association.

Doughty, P. L. I997. “Life goes on: Revisiting Lima’s migrant associations”. En T. Altamirano y L. Hi (eds.). Migrants, regional identities and Latin American cities. American Anthropological Association, Society for Latin American Anthropology Publication Series.

Gabayet, L. I983. "Regional development, industry and workforce: The case of Guadalajara and its region". Tesis de doctorado. University of Durham.

Gilbert, A. 1998. The Latin American City. Edición corregida. Latin American Bureau. Londres.

GolDRING, L. 2004. "Family and collective remittances to Mexico. A multidimensional typology”. Development and Change. 35 (4). 
Hirschman, A. I977. "A generalized linkage approach to development". En F. Hoselitz (ed.). Essays on economic development and cultural change in honor of Bert. Economic Development and Cultural Change, 25. University of Chicago Press. Chicago.

HÜSKEN, F. I99I. "Power, property and parentage in a Central Javanese village”. En F. Hüsken y J. Kemp. Cognition and social organization in Southeast Asia. KITLV Press. Leiden.

IsBeLl, B. J. 1978. To defend ourselves: Ecology and ritual in an Andean village. Waveland Press, Inc. Long Grove, Ill.

LEvitT, P. 1996. Social remittances: A conceptual tool for understanding migration and development. Harvard University Press. Cambridge.

LEVITT, P. y GLICK SCHLLER, N. 2004. “Transnational perspectives on migration: Conceptualizing simultaneity”. International Migration Review.

LONG, N. I986. "The social reproduction of petty commodity enterprise in Central Peru”. En N. Long, J-D van der Ploeg, C. Curtin y L. Box. The commoditization debate: Labor process, strategy, and social network. Agricultural University. Wageningen.

200I. Development sociology: Actor perspectives. Routledge. Londres y Nueva York.

Long, N. y Long, A. (eds.). I992. Battlefields of knowledge: The interlocking of theory and practice in social research and development. Routledge. Londres y Nueva York.

LONG, N. y RoBERTs, B. (eds.). I978. Peasant cooperation and capitalist expansion in Central Peru. Institute of Latin American Studies, University of Texas Press. Austin.

I984. Miners, peasants and entrepreneurs: Regional development in the central highlands of Peru. Cambridge University Press. Cambridge.

2005. "Changing rural scenarios and research agendas in Latin America in the new Century”. En F. Buttel y P. McMichael (eds.). New directions in rural sociology and global development. Elsevier Press. Amsterdam.

Long, N. y Villarreal, M. I998. "Small product, big issues: Value contestations and cultural identities in cross-border commodity networks". Development and Change. 29 (4).

LozANO AscEncio, F. 2005. "Hogares receptores de remesas en México: límites y posibilidades para el desarrollo local y regional”. Artículo presentado en la Conferencia internacional sobre perspectivas mexicanas y estadounidenses, el estudio de la migración internacional. 27 a 29 de enero de 2005, Taxco, Guerrero. 
MAYER, E. 2002. The articulated peasant: Household economies in the Andes. Westview Press. Boulder.

PALERM, J-V. I999. "The expansion of California agriculture and the rise of peasant-worker communities". En Immigration. A civil rights issue for the Americas. Scholarly Resources. Wilmington, Delaware.

2000. "Farmworkers putting down roots in Central Valley communities". California Agriculture. Enero-febrero.

PAERREgaARD, K. I997. Linking separate worlds: Urban migrants and rural lives in Peru. Berg. Oxford y Nueva York.

Portes, A. y Roberts, B. 2005. "Free market city: Latin American urbanization in the years of neoliberal adjustment”. En Studies in comparative international development.

Rodríguez Doig, E. 1994. Entre el campo y la ciudad: estrategias migratorias frente a la crisis. Centro de Estudios para el Desarrollo y la Participación, Cedep. Lima.

SAIGNES, T. I995. "Indian migration and social change in seventeenth-century Charcas”. En B. Larson y O. Harris (eds.). Ethnicity, markets, and migration in the Andes. Duke University Press. Durham y Londres.

SkaR, H. O. I988. The Warm Valley People: Duality and land reform among the Quechua Indians of highland Peru. Göteborgs Etnografiska Museum. Göteborg.

Sмiтh, G. I984. "Confederations of households: Extended domestic enterprises in city and country”. En N. Long y B. Roberts. Miners, peasants and entrepreneurs: Regional development in the central highlands of Peru. Cambridge University Press. Cambridge.

Sorensen, N. N., N. van Hear y P. Engberg-Pedersen. 2002. The migrationdevelopment nexus: Evidence and policy options. IOM (International Organization for Migration). Migration Research Series. 8.

SORENSEN, N. N. 2004. Migrant transfers as a development tool. DIIS (Dansk Institut For Internationale Studier). Copenhagen.

2005. Migrant remittances, development and gender. DIIS (Dansk Institut For Internationale Studier). Copenhagen

TAMAGno, C. 2002. “'You must win their affection...' Migrants' social and cultural practices”. En Work and migration: Life and livelihoods in a globalizing world. Routledge. Londres y Nueva York.

—.2003. “"Entre acá y allá': vidas transnacionales y desarrollo. Peruanos entre Italia y Perú”. Tesis de doctorado. Universidad de Wageningen.

YPEIJ, A. 2000. Producing against poverty: Female and male microentrepreneurs in Lima, Peru. Amsterdam University Press. Amsterdam. 
Modos de vida transnacionales, prácticas organizativas y remesas sociales en Perú

Wikan, UnNi. I990. Managing turbulent hearts. A Balinese formula for living. University of Chicago Press. Chicago. 